\title{
Peripheral Refraction in Myopic Eyes After LASIK Surgery
}

\author{
António Queirós*, César Villa-Collar*, Jorge Jorge*, Ángel Ramón Gutiérrez ${ }^{\dagger}$, \\ and José Manuel González-Méijome*
}

\begin{abstract}
Purpose. To characterize the axial and off-axis refraction across the horizontal meridian of the visual field before and after myopic laser-assisted in situ keratomileusis (LASIK) surgery. This research took place at the Clinical OphthalmologicNovoVisión, Madrid, Spain.

Methods. Twenty-six ODs (mean age \pm SD $=30.4 \pm 4.8$ years) of 26 patients who underwent LASIK surgery to treat myopia between $-0.75 /-3.88 \mathrm{D}$ of spherical equivalent $(\mathrm{M})$ were included in the study. Peripheral refraction was evaluated by an open field auto-refractor before and after LASIK surgery at 3 months. Along with a complete set of examination procedures to assess suitability for treatment, the central and peripheral refractions were measured along the horizontal meridian up to $35^{\circ}$ of eccentricity in the nasal and temporal retinal areas in $5^{\circ}$ visual field steps.

Results. Changes in M ranged between $1.85 \pm 0.93 \mathrm{D}$ at center to $0.33 \pm 0.73 \mathrm{D}$ at $35^{\circ}$ in the nasal retina $(\mathrm{p}<0.029$ for all eccentricities). Treatment induced was symmetric between nasal and temporal visual fields along the horizontal meridian. The degree of myopic increase in relative peripheral refractive error as represented by the spherical equivalent for $30^{\circ}\left(r^{2}=0.462, p<0.001\right)$ and $35^{\circ}\left(r^{2}=0.717, p<0.001\right)$ eccentric refraction was correlated with axial spherical equivalent at baseline.
\end{abstract}

Conclusions. Peripheral refraction is affected by myopic LASIK surgery. Unlike orthokeratology, which increases the peripheral myopia, LASIK reduces myopia across the horizontal visual field out to at least $35^{\circ}$ from fixation.

(Optom Vis Sci 2012;89:977-983)

Key Words: LASIK surgery, peripheral refraction, myopia progression, orthokeratology

T he scientific knowledge on the development of the human eye has evolved dramatically during the last decades from the embryologic, physiological, and functional viewpoints, from the ocular surface to the neural pathway and visual cortex. However, although several risk factors and protector factors have been identified, ${ }^{1,2}$ one of the most enigmatic aspects is still the reason why a given eye can become myopic during ocular development. Myopia is a public health concern affecting about $70 \%$ of the general population in East Asia and about 30\% in the Americas or Europe. ${ }^{3-6}$

Current knowledge suggests that the pattern of peripheral refraction along the horizontal meridian could be involved in the

*PhD, OD

${ }^{\dagger} \mathrm{PhD}, \mathrm{MD}$

Clinical \& Experimental Optometry Research Lab-CEORLab, Center of Physics, Department of Physics, University of Minho, Braga, Portugal (AQ, JJ, JMG$\mathrm{M}$ ), Department of Optics and Optometry, European University of Madrid, Spain (C-VC), and Department of Ophthalmology, University of Murcia, Murcia, Spain (ARG). progression of the refractive error. Although the biological process behind this behavior is not fully understood, the results of Smith et al. ${ }^{7}$ showed in animal models that the visual experience in the peripheral retina could interfere with the ocular growth and the emmetropization process. According to their results, hyperopic peripheral defocus stimulates ocular growth whereas myopic peripheral defocus could prevent ocular growth and consequently limit myopia progression.

Some optical treatments invert the peripheral refractive profile in myopic eyes from relative peripheral hyperopia to relative peripheral myopia. ${ }^{8,9}$ This is associated with changes in the corneal surface by orthokeratology and could be related to lower ocular growth already confirmed in a report of cases ${ }^{10}$ and in controlled trials in Hong Kong, Japan, U.S. and Spain. ${ }^{11-14}$ Furthermore, recent clinical studies have also showed that the peripheral refractive profile along the horizontal meridian could also play a role in the onset and progression of myopia in children, with the premyopic eyes showing hyperopic or less myopic peripheral refractive patterns. ${ }^{15}$ 
Over the last decade, refractive surgery has emerged as an attractive option to people with low-to-moderate refractive errors, particularly in myopic patients. Laser-assisted in situ keratomileusis (LASIK) has allowed millions of people worldwide to reduce their dependence on spectacles or contact lenses.

Although peripheral refractive patterns after orthokeratology have been quite well defined in peer-reviewed literature, ${ }^{8,9}$ such analysis has not been addressed before and after the treatment in the same group of subjects with LASIK surgery. The characterization of peripheral refraction after LASIK surgery has previously been addressed by a work of Ma et al. ${ }^{16}$, where the authors showed that myopic refractive surgery procedures alter the pattern of peripheral focusing toward a more myopic profile beyond the central $20^{\circ}$ of eccentricity. Furthermore, other studies evaluated the impact of the treatment changes in peripheral anterior corneal topography after myopic LASIK, ${ }^{17,18}$ and the impact of corneal first surface aberration after LASIK surgery, with the increase in pupil diameter. ${ }^{19}$ More recently, Mathur and Atchison ${ }^{20}$ have evaluated the peripheral aberrations after LASIK surgery. However, to the best of our knowledge, the study reported here, is the first one using the auto-refraction technique studying the same clinical population before and after LASIK surgery.

Our goal in this study was to prospectively measure the changes in relative peripheral refractive profile across the horizontal meridian in a cohort of patients undergoing myopic LASIK and correlate such changes with baseline refractive error.

\section{METHODS}

\section{Subjects and Inclusion Criteria}

Measurements were obtained from 26 ODs of 26 patients submitted to LASIK using non-customized corneal ablations at the ophthalmological clinic Novovision, (Madrid, Spain). After the nature of the study was explained, each patient signed a consent form before being enrolled. The study was approved by the School of Science (University of Minho, Braga, Portugal) and followed the tenets of the Declaration of Helsinki.

The inclusion criteria required that the subjects did not suffer from any current eye disease or injury and were not taking any ocular or systemic medication. No patient had any history of ocular disease or had undergone previous ocular surgery. Refractive error must have been stable within the last 2 years to be considered for surgery. A complete optometric and ophthalmological examination was performed before surgery. All patients had satisfactory results after the surgery with respect to residual refractive error, visual acuity, regularity, and centering of the treatment zone.

\section{Off-Axis Refraction}

The measurement of central and off-axis refraction was obtained with the open-field Grand Seiko Auto-Refractometer/Keratometer WAM-5500 (Grand Seiko Co., Hiroshima, Japan). This instrument has been previously used and validated to measure refraction in the central ${ }^{21}$ and peripheral visual field. ${ }^{22}$ The system was attached to a custom software developed to automatically record data from the autorefractometer thus avoiding errors in data collection and allowing rapid acquisition to be processed in an Excel spreadsheet for later statistical analysis.
The illumination of the room was adjusted to obtain a pupil size $>4 \mathrm{~mm}$ required to allow off-axis measurements with the Grand Seiko, which was achieved in all cases. The fixation target was placed at a distance of 2.5 meters from the patient's corneal vertex and consisted of 15 LEDs in the horizontal direction: one central, seven to the right, and seven to the left side. The LEDs were separated by an angular distance of $5^{\circ}$ at the patient's position and covered a range of eccentricities of $35^{\circ}$ on each side of the visual field. The subject was seated with the head stabilized in a chin-rest so that the eye was aligned with the central LED. For the OD, the fixation of an object positioned on the right side of the central point (nasal visual field in the eye primary position) matches the temporal retina measures. The OS was occluded while patients kept their head stationary and rotated their ODs to view a series of fixation targets. Five readings were averaged for each position. The axis of the auto-refractor was aligned with the center of the entrance pupil during all measurements.

Descriptive statistics (mean $\pm S D$ ) were obtained for the refraction vector components,

$\mathrm{M}=\mathrm{Sph}+\mathrm{Cyl} / 2, \mathrm{~J} 0=-\mathrm{Cyl} \cdot \cos (2 \theta) / 2$

$$
\text { and } \mathrm{J} 45=-\mathrm{Cyl} \cdot \sin (2 \theta) / 2
$$

according to Fourier analysis, as recommended by Thibos et al., ${ }^{23}$ where Sph, Cyl, and $\theta$ are the manifest sphere, cylinder, and axis, respectively.

\section{LASIK Procedure}

In all cases, the ablation was central, with an optic zone of 6.5 $\mathrm{mm}$ for all LASIK treatments. Surgical routine for LASIK surgery was held according to international standards, and the commonly accepted criteria for refractive surgery procedures were observed regarding predictability, efficacy, and safety. After creating a 120 $\mu \mathrm{m}, 9.5 \mathrm{~mm}$ diameter flap with a Hansatome microkeratome (Chiron Vision, model 2765; Bausch \& Lomb, Claremont, CA), Standard LASIK (Munnerlyn based ${ }^{24}$ ) ablation profiles were produced using the Allegretto Wave Eye-Q- $400 \mathrm{~Hz}$ (Wavelight, Erlangen, Germany). All surgical procedures were uneventful and successful. A minimum of 3 months after treatment was required to guarantee that the topography was completely stable. ${ }^{25}$

\section{Statistical Analysis}

The SPSS software package v.17 (SPSS, Chicago, IL) was used for statistical analysis. Shapiro-Wilk test was applied to evaluate the normality of the data distribution. When normality could not be assumed, the Wilcoxon-signed ranks test was used for paired comparison between baseline and posttreatment values, and paired samples t-test was used when normality could be assumed. The concept of relative peripheral refractive error (RPRE) was used to define the degree of myopia/hyperopia existing or being induced by the treatment at each eccentric location compared with the axial refraction (at a $0^{\circ}$ angle). For a given eccentric location of angle $=\alpha, \Delta \mathrm{RPRE}_{\alpha}=\mathrm{RPRE}_{\alpha \text { (postreatment) }}-\mathrm{RPRE}_{\alpha \text { (pretreatment) }}$, where RPRE $\mathrm{R}_{\alpha \text { (pretreatment) }}=\mathrm{M}_{\alpha \text { (pretreatment) }}-\mathrm{M}_{0}{ }^{\mathrm{o} \text { (pretreatment) }}$ (pretreatment); and $\mathrm{RPRE}_{\alpha \text { (posttreatment) }}=\mathrm{M}_{\alpha \text { (posttreatment) }}-\mathrm{M}_{0}{ }^{\circ}$ (posttreatment) with $M$ being the spherical equivalent as previously defined. Regarding 
correlation analysis between baseline axial refraction (baseline refraction) and change in RPRE averaged for nasal $\left(\triangle R P R E_{\text {nasal }}\right)$ and temporal $\left(\triangle \mathrm{RPRE}_{\text {temporal }}\right)$ eccentric locations at a given angle (5 to $35^{\circ}$ ), Spearman rho correlation was applied when normality could not be assumed, and Pearson correlation was used when normal distribution of data was verified. $\mathrm{p}$ values lower than 0.05 were considered statistically significant.

\section{RESULTS}

Mean age was $30.4 \pm 4.8$ years (ranging from 20 to 37 years) for the 26 subjects of which 11 were female $(42.3 \%)$ and 15 were male (57.7\%). Average preoperative spherical equivalent was $-2.12 \pm$ $0.92 \mathrm{D}$ ranging from -0.75 to $-3.88 \mathrm{D}$. The time between preand postsurgical treatment measures was $124.3 \pm 12.8 \mathrm{~d}$.

\section{Changes in Axial and Off-Axis Refraction After LASIK}

Table 1 presents descriptive statistics for refractive components $\mathrm{M}, \mathrm{J} 0$, and $\mathrm{J} 45$ in the center of the visual field at baseline and after surgery as well as comparisons between them. Statistically significant differences were found for the spherical equivalent (diff postpre $=+1.98 \pm 0.91 \mathrm{D}, \mathrm{p}<0.001$, paired samples t-test) but not for the astigmatic components J0 ( $\mathrm{p}=0.647$, Wilcoxon-signed ranks test) and J45 ( $\mathrm{p}=0.929$, Wilcoxon-signed ranks test).

Vector analysis of refractive components is illustrated in Fig. 1 for baseline data and after treatment. Spherical equivalent refraction shows a statistically significant myopic reduction in all points of the visual field under analysis. Within the central $50^{\circ}$, change in $\mathrm{M}$ component ranged from a minimum of $1.20 \pm 0.69 \mathrm{D}(\mathrm{p}<$ 0.001 , paired samples t-test) at the nasal $25^{\circ}$ location up to a maximum of $1.85 \pm 0.93 \mathrm{D}$ ( $\mathrm{p}<0.001$, paired samples $\mathrm{t}$-test $)$ at center. For astigmatism components, no clinical significant differ-

\section{TABLE 1.}

Demographic characteristics (mean $\pm \mathrm{SD}$, maximum, and minimum) of the population at the baseline, after LASIK surgery, the mean difference and $p$ value between them (refractive error obtained with subjective refraction for central refraction)

\begin{tabular}{ccccc}
\hline & $\begin{array}{c}\text { Pre-LASIK } \\
\text { Mean } \pm \text { SD } \\
\text { Min/max }\end{array}$ & $\begin{array}{c}\text { Post-LASIK } \\
\text { Mean } \pm \text { SD } \\
\text { Min/max }\end{array}$ & $\begin{array}{c}\text { Post- minus } \\
\text { pre-LASIK } \\
\text { Mean } \pm \text { SD }\end{array}$ & p \\
\hline M (D) & $-2.12 \pm 0.92$ & $-0.14 \pm 0.28$ & $+1.98 \pm 0.91$ & $\mathbf{< 0 . 0 0 1}^{\text {a }}$ \\
& $-3.88 /-0.75$ & $-0.79 / 0.38$ & & \\
$J_{0}$ (D) & $0.16 \pm 0.38$ & $0.13 \pm 0.18$ & $-0.03 \pm 0.34$ & $0.647^{b}$ \\
& $-0.50 / 1.13$ & $-0.17 / 0.50$ & & \\
$J_{45}$ (D) & $-0.03 \pm 0.12$ & $0.00 \pm 0.14$ & $+0.03 \pm 0.19$ & $0.929^{b}$ \\
& $-0.32 / 0.24$ & $-0.29 / 0.28$ & & \\
K (D) & $43.78 \pm 1.42$ & $42.01 \pm 1.67$ & $+1.77 \pm 0.83$ & $\mathbf{0 . 0 0 1}^{b}$ \\
& $39.07 / 44.89$ & $41.17 / 45.81$ & &
\end{tabular}

Statistically significant differences between pre- and post-LASIK surgery highlighted in bold.

$\mathrm{K}=$ mean of steep keratometry and flat keratometry, $\mathrm{M}, \mathrm{J} 0$, and J45 are refractive components.

apaired sample t-test.

${ }^{b}$ Wilcoxon-signed rank test. ences exist for the $\mathrm{J} 0$ component within the central $30^{\circ}\left(15^{\circ}\right.$ to each side), but a significant increase in astigmatism is observed beyond this point. This component increases about $-0.50 \mathrm{D}$ or more for eccentricities beyond $25^{\circ}$ on each side of the visual field. Conversely, no consistent significant changes were noticed across the field for the J45 component. In the post-LASIK peripheral refraction, comparing points located symmetrically to both sides of the central refraction, there were no statistically significant differences in $\mathrm{M}$ components ( $\mathrm{p}>0.290$, paired samples t-test), nor for J45 ( $p>0.174$, Wilcoxon-signed ranks test). For the J0 component, only at eccentricity $5^{\circ}(\mathrm{p}=0.323$, paired samples t-test $)$ and $15^{\circ}$ $(p=0.905$, paired samples t-test) was there no significant difference between nasal and temporal sides.

\section{Symmetry of Refractive Profile vs. Eccentricity}

Fig. 2 represents a summary of the relative changes of refraction compared with baseline for different components of refraction $\mathrm{M}$, $\mathrm{J} 0$, and $\mathrm{J} 45$. These data represent relative values of refraction where all the curve was shifted to set the central refractive value at "zero," enhancing the visibility of the relative changes in peripheral refraction compared with central measurement. Comparing points located symmetrically to both sides of the central refraction, there were no statistically significant differences in $\mathrm{M}$ component, J0, and J45 between nasal and temporal corresponding points.

When each eccentric point was compared with central measurement, results showed that differences in relative spherical equivalent $\mathrm{M}$ among different eccentric points became only statistically significant (i.e., where does the significant relative peripheral myopia start), for the nasal retina beyond $20^{\circ}$ (i.e., $\mathrm{p}<0.05$ only for $25^{\circ}$ and beyond according to paired samples t-test), and for the temporal retina beyond $15^{\circ}$ (i.e., $\mathrm{p}<0.05$ only for $20^{\circ}$ and beyond according to Wilcoxon-signed ranks test). Regarding changes in $\mathrm{J} 45$, none of the points analyzed were statistically different from axial refraction. Regarding changes in J0 component, all points except the central ones $\left(20^{\circ}\right.$ nasal to $15^{\circ}$ temporal) showed statistically significant differences when compared with changes in axial refraction.

Fig. 3 compares LASIK $(n=26)$ and orthokeratology ${ }^{9}(n=$ 28 ), on the relative peripheral refraction pattern (post-minus pretreatment). Changes in spherical equivalent refraction showed similar results between both treatments within the central area from $15^{\circ}$ nasal and $10^{\circ}$ temporal $(\mathrm{p}>0.144$, Mann-Whitney $\mathrm{U}$; maximum difference: $-0.16 \pm 0.74 \mathrm{D})$. Beyond those eccentric locations orthokeratology induced higher changes in relative peripheral refraction than LASIK (temporal retina, $\mathrm{p}<0.033$, Mann-Whitney U). Changes in spherical equivalent refraction were symmetric between nasal and temporal visual field along the horizontal meridian ( $p>0.050$ for nasal vs. temporal paired comparisons for all eccentricities in LASIK and orthokeratology). Offaxis refraction is more affected by orthokeratology than myopic LASIK surgery, particularly in the temporal retina.

\section{Off-Axis Myopia After LASIK vs. Baseline Axial Refraction}

Table 2 presents the correlation analysis between the degree of change in RPRE induced by LASIK (average of $\triangle \mathrm{RPRE}_{\text {nasal }}$ and 

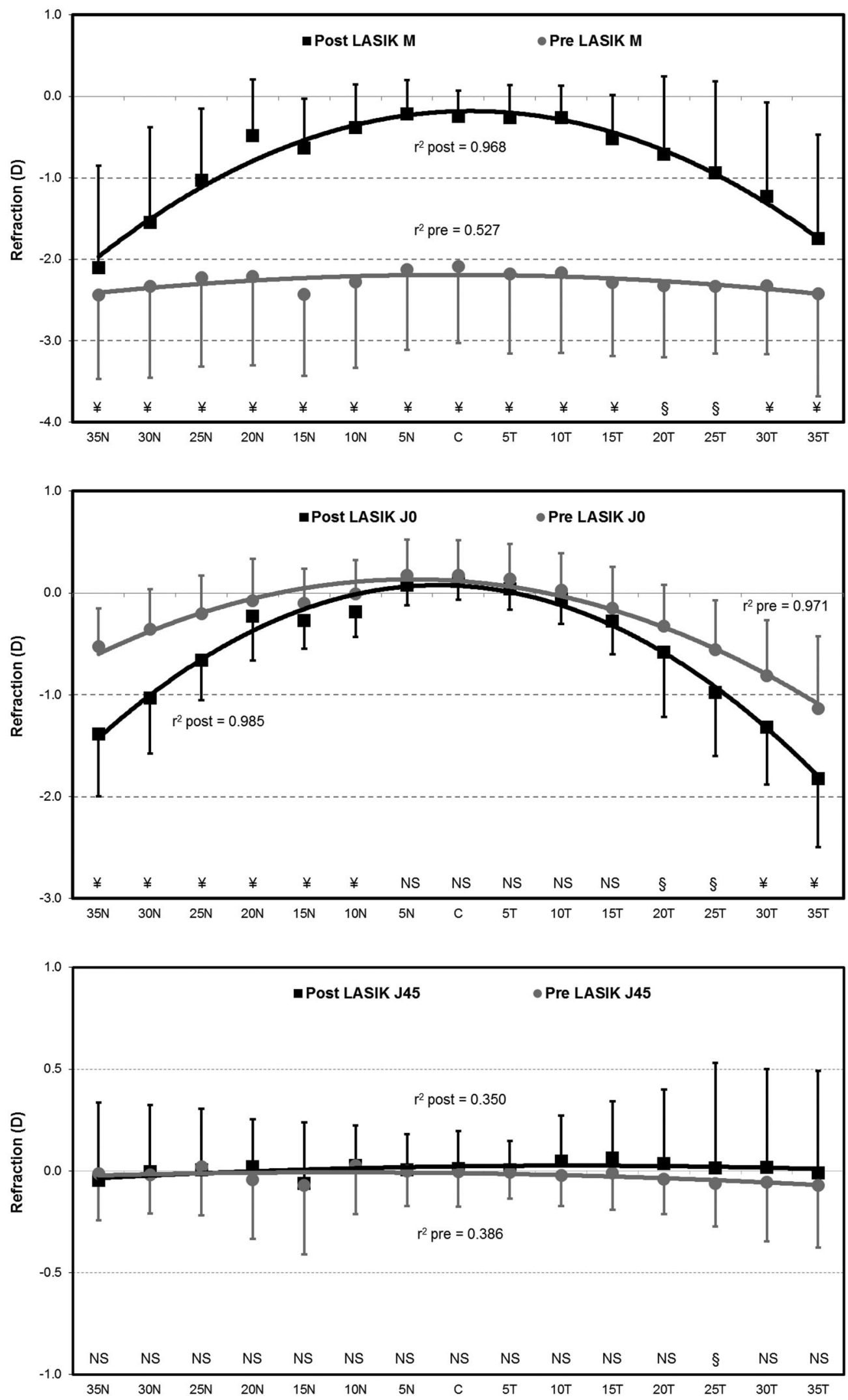

\section{FIGURE 1.}

Spherical equivalent M (Top) and cylindrical components J0 (center) and J45 (bottom) refraction as a function of field angle in LASIK surgery patients in the temporal $(\mathrm{T})$ and nasal $(\mathrm{N})$ retinal areas, at baseline (gray circles), and after treatment (black squares). Bars represent SDs. Statistical significant

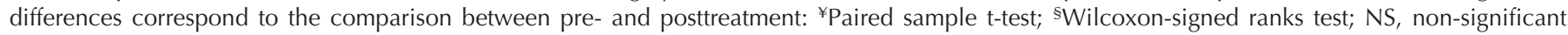
values. Lines represent the second order polynomial fit for $M\left(y_{\text {post }}=-0.034 x^{2}+0.561 x-2.492, r^{2}=0.968\right.$ and $y_{\text {pre }}=-0.005 x^{2}+0.073 x-$ $\left.2.478, r^{2}=0.527\right)$; for J0 ( $y_{\text {post }}=-0.034 x^{2}+0.522 x-1.910, r^{2}=0.985$ and $\left.y_{\text {pre }}=-0.020 x^{2}+0.279 x-0.856, r^{2}=0.971\right)$; and for J45 $\left(y_{\text {post }}=\right.$ $-0.0007 x^{2}+0.015 x-0.050, r^{2}=0.350$ and $\left.y_{\text {pre }}=-0.0007 x^{2}+0.008 x-0.029, r^{2}=0.386\right)$. 


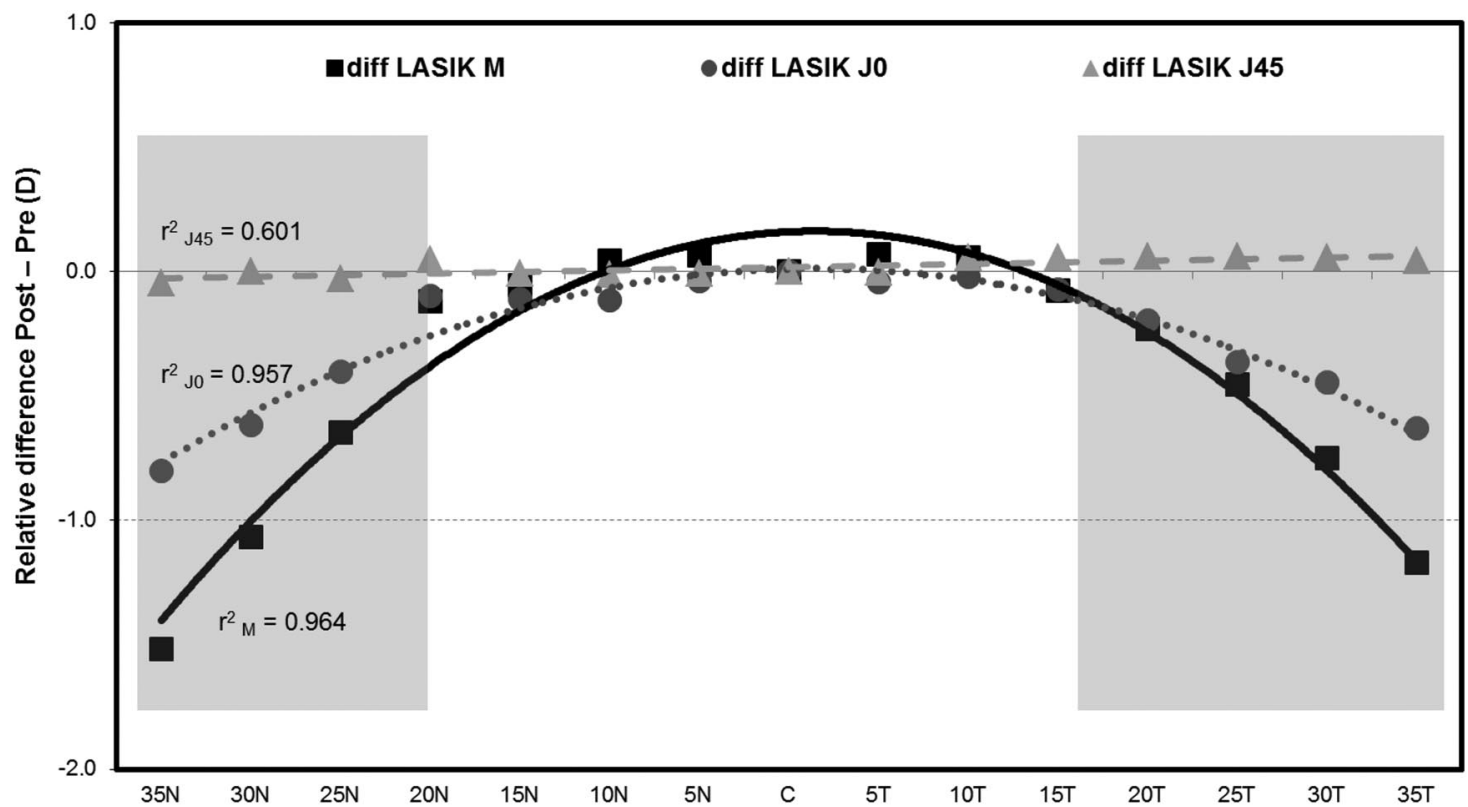

FIGURE 2.

Relative differences (post - pretreatment) in components of refraction as a function of field angle in LASIK surgery patients in the temporal (T) and nasal $(\mathrm{N})$ retinal area. The shaded area represents the points where the changes in off-axis spherical equivalent $(\mathrm{M})$ are significantly more myopic $(\mathrm{p}<0.05)$ than those induced in the central visual axis. Lines represent the second order polynomial fit for $\mathrm{M}\left(\mathrm{y}_{\text {diff }}=-0.030 \mathrm{x}^{2}+0.488 \mathrm{x}-1.862, \mathrm{r}^{2}=0.964\right)$; for J0 ( $\left.y_{\text {diff }}=-0.015 x^{2}+0.244 x-0.996, r^{2}=0.957\right)$; and for J45 $\left(y_{\text {diff }}=-2 E-05 x^{2}+0.007 x-0.034, r^{2}=0.601\right)$.

Relative Post - Pre (LASIK vs OK)

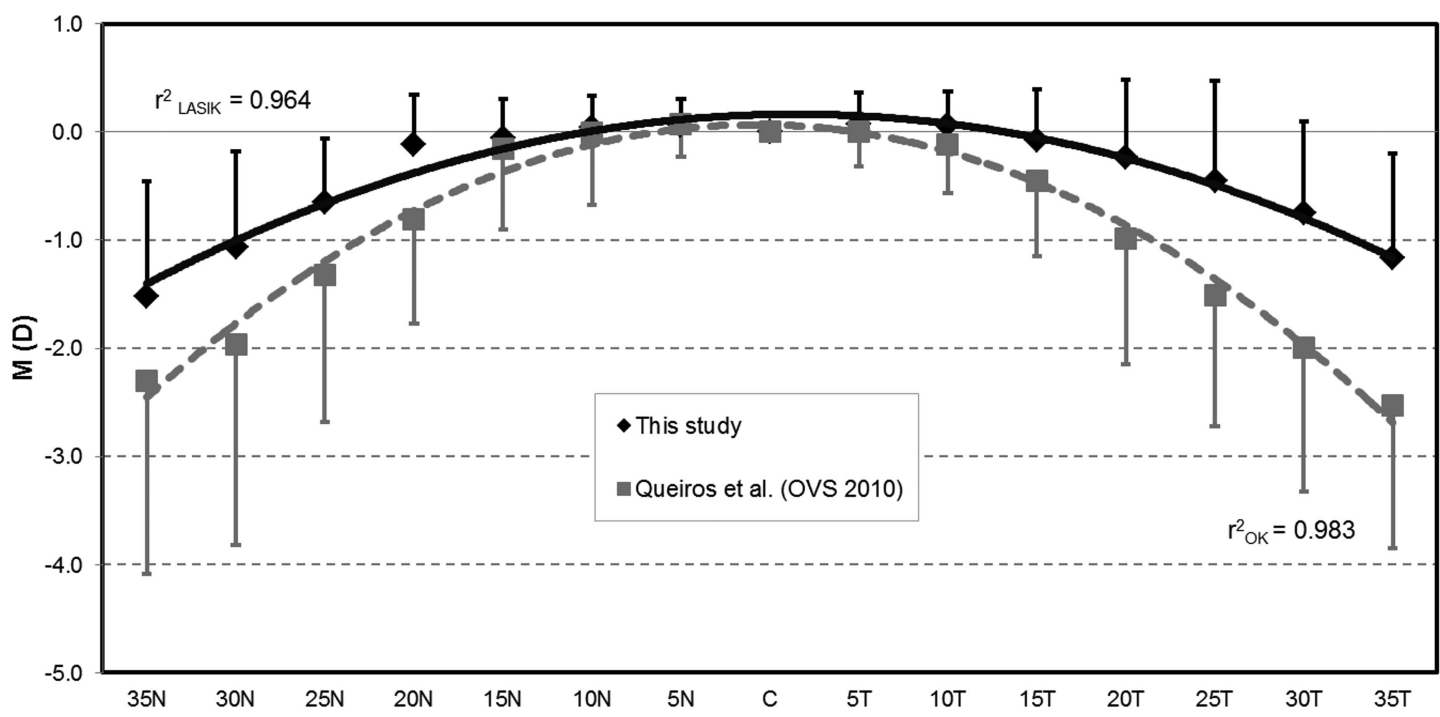

FIGURE 3.

Relative peripheral refraction pattern (posttreatment - pretreatment) of LASIK $(n=26)$ and orthokeratology ${ }^{9}(O K, n=28)$.

$\Delta \mathrm{RPRE}_{\text {temporal }}$ ) from 5 to $35^{\circ}$ locations as a function of baseline $\mathrm{M}$ component $\left(\mathrm{M}_{0}^{\circ}\right)$. Correlations were progressively lower from $35^{\circ}$ $\left(\mathrm{r}^{2}=0.717 ; \mathrm{p}<0.001\right)$ to $5^{\circ}\left(\mathrm{r}^{2}=0.001 ; \mathrm{p}=0.986\right)$. Fig. 4 shows the graphical representation of these correlations for $30^{\circ}$ and $35^{\circ}$ as being those reflecting the highest correlations with baseline spherical equivalent refraction $\left(\mathrm{M}_{0}^{\circ}\right)$.

\section{DISCUSSION}

This study shows that the pattern of peripheral refraction changes significantly after LASIK surgery. This change in periph- eral focusing of the postsurgical eye is statistically significant beyond the central $35^{\circ}$ of the central visual field. This behavior has been well described in the literature in the form of spherical aberration induced by central ablations for myopic treatments as measured with wavefront sensors. ${ }^{19,26,27}$ However, no previous studies have addressed the clinical measurement of the peripheral refraction before and after LASIK treatments. Although these outcomes are negative in terms of optical quality of the eye, there is a rationale to think that they could be beneficial preventing myopia progression. 
TABLE 2.

Correlations between change in RPRE after LASIK surgery for a given relative peripheral eccentric location $\left[\operatorname{RPRE}_{M}\right.$ nasal + $\operatorname{RPRE}_{M}$ temporal $/ 2$ ] and the axial spherical equivalent at baseline

\begin{tabular}{lcc}
\hline Eccentricity $\left(^{\circ}\right)$ & Correlation $\left(\mathrm{r}^{2}\right)$ & $\mathrm{p}$ (Significance) \\
\hline 35 & $0.717^{\mathrm{a}}$ & $<0.001$ \\
30 & $0.462^{\mathrm{b}}$ & $<0.001$ \\
25 & $0.264^{\mathrm{b}}$ & 0.007 \\
20 & $0.085^{\mathrm{a}}$ & 0.148 \\
15 & $0.053^{\mathrm{a}}$ & 0.256 \\
10 & $0.015^{\mathrm{a}}$ & 0.541 \\
5 & $0.001^{\mathrm{a}}$ & 0.986 \\
\hline
\end{tabular}

$\mathrm{n}=26$ eyes.

apearson correlation.

bspearman rho.

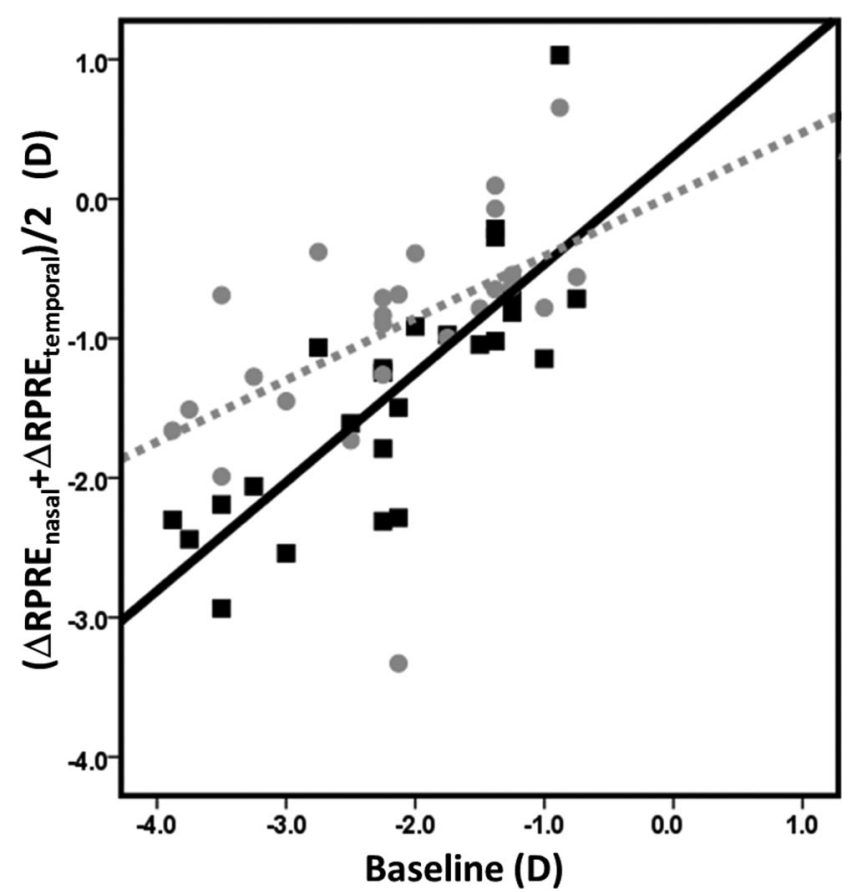

FIGURE 4.

Change in RPRE after LASIK surgery for a given peripheral eccentric location (average of $\triangle R P R E_{\text {nasal }}$ and $\triangle R P R E_{\text {temporal }}$ ) as a function of the axial spherical equivalent at baseline. For clarity, only the higher correlations are shown, corresponding to the $30^{\circ}\left(r^{2}=0.462, y=0.517 x+\right.$ 0.120 , circles, dashed line $)$ and $35^{\circ}\left(r^{2}=0.717, y=0.803 x+0.252\right.$, squares, solid line) eccentric locations.

Previous results from Ma et al. ${ }^{16}$ showed that myopic LASIK procedures can alter the pattern of peripheral refraction toward a more myopic profile beyond the central $20^{\circ}$ of eccentricity (about $40^{\circ}$ of the central visual field). The pioneering work of Ma et al. showed that myopic LASIK surgery renders similar results to those observed more recently with orthokeratology in terms of change in peripheral refractive profile refraction either in young adults ${ }^{8,9}$ and children. ${ }^{28}$

Our results show that it is possible to induce a change in the RPRE with LASIK, so that the peripheral visual field will be myopic after the procedure, whereas the central visual field within the optic zone created by the laser will be emmetropic. This correlates well with previous results reported in terms of central and peripheral corneal curvature after refractive surgery. ${ }^{17}$ Our results are consistent with the previous descriptions made by Ma et al., ${ }^{16}$ regarding area undergoing peripheral myopization $\left(40^{\circ}\right.$ in their results, $35^{\circ}$ of the visual field in our results).

Although orthokeratology treatment results in a more myopic peripheral refraction when compared with baseline values, LASIK does not appear to induce such a change (Fig. 3). Instead, LASIK warrants that the focalization in the peripheral visual field remains myopic after the procedure, but at a lower rate compared with baseline rather than being increased as it happens in orthokeratology. ${ }^{9}$ As we have previously demonstrated in orthokeratology, ${ }^{9}$ and now in LASIK patients, peripheral relative myopization is strongly correlated with baseline myopia. Although the average baseline myopia in this LASIK cohort was slightly higher than in our previous orthokeratology study, peripheral relative myopia after LASIK was lower than in the orthokeratology group. These results are consistent with previous findings reporting lower levels of steepening of the front corneal surface after LASIK compared with orthokeratology. ${ }^{17}$ The tissue redistribution in orthokeratology, as opposed to the ablation of central tissue in LASIK, is the main reason for the greater increase in paracentral corneal power observed with orthokeratology. ${ }^{17}$ Additionally, larger optical zone and smoother transition area contribute to lower relative peripheral myopia after LASIK.

However, the application of refractive surgery in children is controversial. ${ }^{29,30}$ Although intraocular lens implantation in children with cataract is fully accepted by the clinical and scientific community, the same is not applicable to refractive corneal surgery with cosmetic purposes. Conversely, there are several reports of therapeutic applications of radial keratotomy in teenagers, ${ }^{31}$ and numerous reports of laser-assisted procedures in high bilateral myopia, ${ }^{32,33}$ as well as myopic and hyperopic anisometropia ${ }^{34,35}$ to prevent refractive and anisometropic amblyopia, respectively.

Regarding the LASIK potential to prevent myopia progression, there are numerous reports that support the stability of refractive error after LASIK surgery, and considering the present results, might be argued that the profile of refractive focalization after the procedure might be involved. However, the main limitation to understand such a potential is that most of the published studies have been performed in adult patients where myopia is considered non-progressive. However, there are in the literature several reports about the application of LASIK to correct myopia in children aged $\leq 12$ years. At this age, the myopia refractive error might be still developing as has been shown by several studies. ${ }^{36,37}$

In summary, given the results reported in this article, the pattern of peripheral focusing created by LASIK surgery might play a role in preventing myopia progression, by creating a myopic defocus in the paracentral and peripheral retina. However, there are numerous controversies surrounding the potential of corneal refractive surgery in the prevention of myopia progression.

\section{ACKNOWLEDGMENTS}

This study was supported by a grant (SFRH/BD/61,768/2009, António Queiros) from the Science and Technology Foundation of Portuguese, and Ministry of Science and Higher Education (European Social Funding).

Received October 14, 2011; accepted March 2, 2012. 


\section{REFERENCES}

1. Mehdizadeh M, Nowroozzadeh MH. Outdoor activity and myopia. Ophthalmology 2009;116:1229-30.

2. Rose KA, Morgan IG, Ip J, Kifley A, Huynh S, Smith W, Mitchell P. Outdoor activity reduces the prevalence of myopia in children. Ophthalmology 2008;115:1279-85.

3. Jorge J, Almeida JB, Parafita MA. Refractive, biometric and topographic changes among Portuguese university science students: a 3-year longitudinal study. Ophthalmic Physiol Opt 2007;27:287-94.

4. Saw SM, Katz J, Schein OD, Chew SJ, Chan TK. Epidemiology of myopia. Epidemiol Rev 1996;18:175-87.

5. Morgan I, Rose K. How genetic is school myopia? Prog Retin Eye Res 2005;24:1-38.

6. Vitale S, Sperduto RD, Ferris FL, $3^{\text {rd }}$. Increased prevalence of myopia in the United States between 1971-1972 and 1999-2004. Arch Ophthalmol 2009;127:1632-9.

7. Smith EL, $3^{\text {rd }}$, Kee CS, Ramamirtham R, Qiao-Grider Y, Hung LF. Peripheral vision can influence eye growth and refractive development in infant monkeys. Invest Ophthalmol Vis Sci 2005;46:3965-72.

8. Charman WN, Mountford J, Atchison DA, Markwell EL. Peripheral refraction in orthokeratology patients. Optom Vis Sci 2006;83:641-8.

9. Queirós A, Gonzalez-Meijome JM, Jorge J, Villa-Collar C, Gutierrez AR. Peripheral refraction in myopic patients after orthokeratology. Optom Vis Sci 2010;87:323-9.

10. Cheung SW, Cho P, Fan D. Asymmetrical increase in axial length in the two eyes of a monocular orthokeratology patient. Optom Vis Sci 2004;81:653-6.

11. Cho P, Cheung SW, Edwards M. The longitudinal orthokeratology research in children (LORIC) in Hong Kong: a pilot study on refractive changes and myopic control. Curr Eye Res 2005;30:71-80.

12. Walline JJ, Jones LA, Sinnott LT. Corneal reshaping and myopia progression. Br J Ophthalmol 2009;93:1181-5.

13. Santodomingo-Rubido J, Villa-Collar C, Gilmartin B, Gutierrez AR. Myopia control with orthokeratology contact lenses in Spain (MCOS): design, baseline findings and 18 month refractive and biometric data. In: Schaeffel F, Feldkaemper M, eds. Myopia: Proceedings of the 13th International Conference. Optom Vis Sci 2011;88:396.

14. Kakita T, Hiraoka T, Oshika T. Influence of overnight orthokeratology on axial elongation in childhood myopia. Invest Ophthalmol Vis Sci 2010;52:2170-4.

15. Mutti DO, Hayes JR, Mitchell GL, Jones LA, Moeschberger ML, Cotter SA, Kleinstein RN, Manny RE, Twelker JD, Zadnik K. Refractive error, axial length, and relative peripheral refractive error before and after the onset of myopia. Invest Ophthalmol Vis Sci 2007;48:2510-9.

16. Ma L, Atchison DA, Charman WN. Off-axis refraction and aberrations following conventional laser in situ keratomileusis. J Cataract Refract Surg 2005;31:489-98.

17. Queirós A, Gonzalez-Meijome JM, Villa-Collar C, Gutierrez AR, Jorge J. Local steepening in peripheral corneal curvature after corneal refractive therapy and LASIK. Optom Vis Sci 2010;87:432-9.

18. Gonzalez-Meijome JM, Sanudo-Buitrago F, Lopez-Alemany A, Almeida JB, Parafita MA. Correlations between central and peripheral changes in anterior corneal topography after myopic LASIK and their implications in postsurgical contact lens fitting. Eye Contact Lens 2006;32:197-202.

19. Queirós A, Villa-Collar C, Gonzalez-Meijome JM, Jorge J, Gutierrez AR. Effect of pupil size on corneal aberrations before and after standard laser in situ keratomileusis, custom laser in situ keratomileusis, and corneal refractive therapy. Am J Ophthalmol 2010;150:97-109.

20. Mathur A, Atchison DA. Influence of spherical intraocular lens implan- tation and conventional laser in situ keratomileusis on peripheral ocular aberrations. J Cataract Refract Surg 2010;36:1127-34.

21. Queirós A, Gonzalez-Meijome J, Jorge J. Influence of fogging lenses and cycloplegia on open-field automatic refraction. Ophthalmic Physiol Opt 2008;28:387-92.

22. Queirós A, Jorge J, Gonzalez-Meijome JM. Influence of fogging lenses and cycloplegia on peripheral refraction. J Optom 2009;2: 83-9.

23. Thibos LN, Wheeler W, Horner D. Power vectors: an application of Fourier analysis to the description and statistical analysis of refractive error. Optom Vis Sci 1997;74:367-75.

24. Munnerlyn CR, Koons SJ, Marshall J. Photorefractive keratectomy: a technique for laser refractive surgery. J Cataract Refract Surg 1988; 14:46-52.

25. Holladay JT, Dudeja DR, Chang J. Functional vision and corneal changes after laser in situ keratomileusis determined by contrast sensitivity, glare testing, and corneal topography. J Cataract Refract Surg 1999;25:663-9.

26. Anera RG, Villa C, Jimenez JR, Gutierrez R. Effect of LASIK and contact lens corneal refractive therapy on higher order aberrations and contrast sensitivity function. J Refract Surg 2009;25:277-84.

27. Kohnen T, Mahmoud K, Buhren J. Comparison of corneal higherorder aberrations induced by myopic and hyperopic LASIK. Ophthalmology 2005;112:1692.

28. Kang P, Swarbrick H. Peripheral refraction in myopic children wearing orthokeratology and gas-permeable lenses. Optom Vis Sci 2011; 88:476-82.

29. Fecarotta CM, Kim M, Wasserman BN. Refractive surgery in children. Curr Opin Ophthalmol 2010;21:350-5.

30. Daoud YJ, Hutchinson A, Wallace DK, Song J, Kim T. Refractive surgery in children: treatment options, outcomes, and controversies. Am J Ophthalmol 2009;147:573.e2-82.e2.

31. O'Dell LW, Wyzinski P. Radial keratotomy in teenagers. I. A practical approach. Refract Corneal Surg 1989;5:315-8.

32. Tychsen L, Hoekel J. Refractive surgery for high bilateral myopia in children with neurobehavioral disorders: 2 . Laser-assisted subepithelial keratectomy (LASEK). J AAPOS 2006;10:364-70.

33. Astle WF, Huang PT, Ingram AD, Farran RP. Laser-assisted subepithelial keratectomy in children. J Cataract Refract Surg 2004;30: 2529-35.

34. Astle WF, Rahmat J, Ingram AD, Huang PT. Laser-assisted subepithelial keratectomy for anisometropic amblyopia in children: outcomes at 1 year. J Cataract Refract Surg 2007;33:2028-34.

35. Yin ZQ, Wang H, Yu T, Ren Q, Chen L. Facilitation of amblyopia management by laser in situ keratomileusis in high anisometropic hyperopic and myopic children. J AAPOS 2007;11:571-6.

36. Pointer JS. A 6-year longitudinal optometric study of the refractive trend in school-aged children. Ophthalmic Physiol Opt 2001;21:361-7.

37. Fan DS, Cheung EY, Lai RY, Kwok AK, Lam DS. Myopia progression among preschool Chinese children in Hong Kong. Ann Acad Med Singapore 2004;33:39-43.

António Queirós

Clinical \& Experimental Optometry Research Lab Department of Physics (Optometry) Campus Gualtar

University of Minho 4710-057 Braga-Portugal e-mail:aqp@fisica.uminho.pt 